\title{
Glass Properties Selection Effect on LEED Points for Core and Shell High Rise Residential Building in Jordan
}

\author{
Ammar Alkhalidi $^{a}, *$, Hasan Jarad ${ }^{b}$, Mohammad Juaidy $^{b}$ \\ ${ }^{a}$ Department of Energy Engineering, German Jordanian University, P.O. Box 35247, Amman 11180 Jordan \\ ${ }^{b}$ Mechanical Engineering, JEA Associate engineer, Arabtec Jardaneh Engineers and Architects, Amman, Jordan
}

\begin{abstract}
Green building concept is flourishing in developing countries due to the high-energy cost. To meet the green building requirement, this paper investigate the effect of glass properties on 4 and 20 story building total, heating and cooling, loads for variable glass-wall ratios using HAP4.5 . The ratios considered are $20 \%, 40 \%, 60 \%, 80 \%$ \& $100 \%$ glass to wall. The simulations were carried out for both building under moderate climate, Amman, Jordan was the selected city from this climatic zone. The glass overall heat transfer (U-value) \& shading coefficient (S.C) are paired in nine combinations, these pairs are called Combination Number (CN). Combination Number simulate all range of glass properties, $\mathrm{CN} 1$ is the worst case to 9 the best glass properties. Results showed that the minimum impact of glass properties was on 20-percentile glass to wall ratio and maximum at 100 Percentile. On the other hand, a Maximum of 10 LEED point could be achieved in the 20-percentile and 16 point in the case of 100-persentile for both 20 and 4 story building. Data found in this paper where formulated in the following equations with $\mathrm{R}^{2}=0.949$.
\end{abstract}

$$
\begin{aligned}
& 4 \text { Story Total Load }=915514-(63546 * C N)+(9770 * \text { Glass to wall }) \\
& 20 \text { Story Total Load }=7638346-(540386 * C N)+(84090 * \text { Glass to wall })
\end{aligned}
$$

Keywords: Green Building, LEED Points, Glass Properties Effect

\section{Introduction}

Promoting energy efficiency in buildings is a measure of increasing importance taken to reduce energy use in buildings. This is essential to cope with measure problems such as the lacking and depleting primary energy resources as well as the rise in greenhouse gases emissions. In developing and emerging countries, the increasing energy demand is considered serious challenges that encounter development. In view of such a challenge engineers and designers tend to introduce smart design measures that would save energy at all levels. Energy cost and shortage derives Jordanian engineers more in the green building and energy saving direction. Governmental interest toward green building have grown in the last years. Nowadays, more and more interest in techniques of evaluating energy efficacy in building are adapted in Jordan like Leadership in Energy and Environmental Design (LEED) system. Improved glass thermal

${ }^{*}$ Corresponding author. Tel.: +96264294444

E-mail: ammar.alkhalidi@gju.edu.jo

(C) 2016 International Association for Sharing Knowledge and Sustainability

DOI: 10.5383/ijtee.13.01.006 properties and its effect on LEED points is one of such measures that was adoption due to its direct impact on the cooling and heating load, which is considered a major element in power consumption in any building. Some engineering approaches tend to minimize glass solar effect by enhancing the glass thermal properties to directly influence the cooling and heating load of the building. These approaches do not take normally into considerations glass-wall ratio that has a significant effect to the total thermal load of the building there for it will have major impact in glass properties selection. When implementing such approaches into building design, designers end up with highly improved glass properties no matter how much it is feasible to adopt those glass types.

In this paper, overall heat transfer coefficient (U) and shading coefficient (S.C.) were investigated for five different glass ratios (20, 40, 60, 80 and $100 \%)$ to find the energy saving and corresponding LEED points in 20-storey and 4-story residential building. 


\section{Literature Review}

Authors in literature review focused on the payback period and the feasibility of enhancing thermal properties of glass. Accordingly, they recommend reducing the windows area in the south oriented façade of the building to minimize solar heat gain during the day hours [5, 6, and 7].

Among many researchers of this sector, the majority tried to optimize the glass to wall construction ratio in residential buildings by finding the best combination between glass and walls areas to satisfy the day light requirement and the enhanced thermal properties to minimize cooling load simultaneously.

R.J. Fuller [5] showed in his research that a saving of $31.4 \%$ in annual cooling energy requirements and $36.8 \%$ of the peak cooling load for investigated base case apartment can be achieved with his approach that is based on reducing glass area and reducing both $\mathrm{U}$ value and shading coefficient. However, all the passive strategies have marginal effect on latent cooling load, which is often less than $1 \%$.

Mohammad and Al-Homoudin [6] implemented an optimization model to the design energy conserving air-conditioned residential buildings in different climatic regions. He presented optimum sets of building design variables for typical U.S. and Saudi residences with the main objective of minimizing annual power consumption in these buildings. Optimization results showed that significant energy savings could be achieved by applying optimization measures, in terms of both glass properties and exterior walls conductivity, in the thermal design of buildings. Valuable design information on the selection and arrangement of various building components can be obtained in the early stages of the building design process through the implementation of optimization techniques similar to the model used.

Mehlika et al. [7] established optimum building aspect ratios and south window sizes of residential buildings from thermal performance point of view. The effects of six different building aspect ratios and eight different south window sizes for each building aspect ratio were analyzed for apartments located at intermediate floors of buildings, by the aid of the computer based thermal analysis program SUNCODE-PC in five cities of Turkey: Erzurum, Ankara, Diyarbakir, Izmir, and Antalya. The results were evaluated in terms of annual energy consumption and the optimum values are driven. Comparison between optimum values and the total energy consumption rates was made for the analyzed cities.

Hong et al. [8] described how a design day for building energy performance simulation that could be selected from a 'typical meteorological year' of a location. The advantages of the design day weather file are its simplicity and flexibility in use with simulation programs. To validate the versatility of the design day weather file, we compare simulation results of the peak load and load problem of a building obtained from the DOE-2.1E code and a specially developed load estimation program, PEAKLOAD. PEAKLOAD is developed using the transfer function method and ASHRAE databases.
Flodberg et al. [9] Investigated the design features affecting energy use in office buildings and suggests the optimal lowenergy design from a Swedish perspective. Dynamic simulations have been carried out with IDA ICE 4 on a typical narrow office building with perimeter cell rooms. The results from the parametric study reveal that the most important design features for energy saving are demand-controlled ventilation as well as limited glazing on the façade.

Magli et al. [10] Urban areas usually experience higher temperatures when compared to their rural surroundings. Several studies underlined that specific urban conditions are strictly connected with the urban heat island (UHI) phenomenon, which consists in the environmental overheating related to anthropic activities.

Valdiserri et al. [11] investigated the building envelope should be equipped with insulated walls and high-efficiency windows. This approach leads to considerable thermal insulation, but at the same time, in the absence of a suitable ventilation system, it results in a worsening of indoor air quality. A healthy quality of life requires good indoor air quality; especially in places where people spend most of their time, adequate air exchanges should be guaranteed and indoor pollution reduced to "acceptable", levels.

Literature showed a lack of understanding about Jordanian building style and energy saving in green building, this paper will show the effect of glass properties on energy demand reflect on LEED points.

\section{Methodology}

In this research, the hourly weather data of Amman, Jordan are used in HAP4.5 [12, 13] software to simulate the total, heating and cooling, load for 20-storey and 4-story residential building. Glass properties effect on the total load was investigate for different wall to glass ratios (20\%-100\%) in the building. 4 and 20 story building was chosen as they are the most common building story in Jordan. ASHREA 90.1 minimum requirements for glass were used as a starting point for calculation. Results were subsequently compared to LEED requirements to define threshold of energy saving in this paper.

LEED points were selected in this paper, as it is a third party certification program and the nationally accepted benchmark for the design, construction and operation of high performance green buildings. LEED certification is available for all building types including new construction and major renovation; existing buildings; commercial interiors; core and shell; schools and homes. This system was developed by the U.S. Green Building Council in 2000 through a consensus based process, and serves as a tool for buildings of all types and sizes. LEED is a pointbased system where building projects earn LEED points for satisfying specific green building criteria.

Worst-case scenario was chosen in building direction with the longest side of the building directed to south. Building layout is presented in Figure 1 


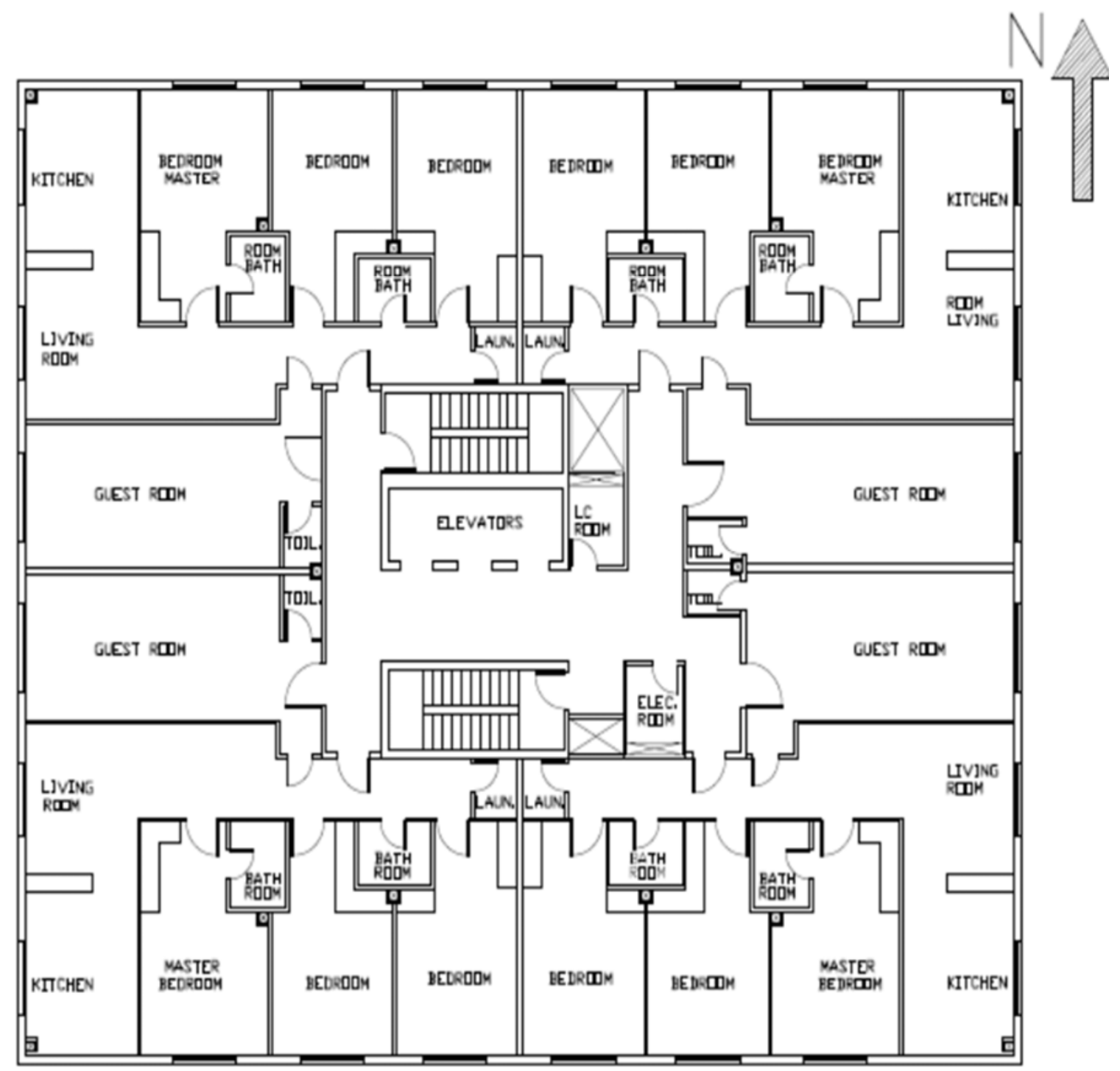

Figure 1: Layout of the typical floor in the simulated building

The thermal performance of the 20 and 4-story residential building was investigated, the selected number of floors and layout, shown in Fig.1, and are very common in Jordanian building. Hourly simulation of the cooling and heating systems operating all year round was done using the hourly simulation software HAP 4.5.

HAP software is a commonly used software in estimating the heating and cooling load for building even it had been used as validation method for other newer technologies as in Ray et al. [14] where it had been used to validate newly proposed method called Building Energy Analysis methodology. Sait [15] compared the resulted from HAP software to calculated loads by excel sheet and found a very good agreement between both results with slight variation due to defining the thermal resistance for the used materials of the wall, roof, and windows. In addition, the sources of constants used for the equations are not the same. Amman design Parameters are presented in Table 1 below.
Table 1 showed simulation design parameter for Amman Jordan, Table 2 shows building parameter used in the computer simulations. The glass solar properties were varied along with changing glass-wall ratio for both 4 and 2 Story building. Glass properties are presented in Table 3.

Glass properties, overall heat transfer coefficient (U) and shading coefficient (S.C.) presented in table 3, are paired in nine combinations. these pairs are called Combination Number (CN). The minimum requirements for glass properties, given $\mathrm{CN} 1$, was selected from ASREA 90.1 standard to be $\mathrm{U}=3.4$ and S.C. 0.25 . The energy consumption used in the building while using CN1 glass will be used as a reference to calculate the energy saving due to improving glass properties. Combination Number increases as glass properties improve, i.e. CN 1 is the worst and 9 the best glass properties. The chosen $\mathrm{CN}$ represent the common combination in the market. 
Table 1: Design Parameters for Amman Jordan.

\begin{tabular}{|l|l|}
\hline City Name & Amman \\
\hline Location & Jordan \\
\hline Latitude & 32.0 Deg. \\
\hline Longitude & -36.0 Deg. \\
\hline Elevation & $773.0 \mathrm{~m}$ \\
\hline Summer Design Dry-Bulb & $35.0^{\circ} \mathrm{C}$ \\
\hline Summer Coincident Wet-Bulb & $18.3^{\circ} \mathrm{C}$ \\
\hline Summer Daily Range & $11.3^{\circ} \mathrm{K}$ \\
\hline Winter Design Dry-Bulb & $0.6^{\circ} \mathrm{C}$ \\
\hline Winter Design Wet-Bulb & $-2.5^{\circ} \mathrm{C}$ \\
\hline Atmospheric Clearness Number & 1.00 \\
\hline Average Ground Reflectance & 0.20 \\
\hline Soil Conductivity & 1.385 W/(m- $\left.{ }^{\circ} \mathrm{K}\right)$ \\
\hline $\begin{array}{l}\text { Local Time Zone (GMT }+/-\mathrm{N} \\
\text { hours) }\end{array}$ & -2.0 hours \\
\hline Consider Daylight Savings Time & Yes \\
\hline Daylight Savings Begins & March, 27 \\
\hline Daylight Savings Ends & September, 26 \\
\hline Simulation Weather Data & Amman (Avg) \\
\hline Current Data & $\begin{array}{l}2001 \text { ASHRAE } \\
\text { Handbook }\end{array}$ \\
\hline Design Cooling Months & January to December \\
\hline
\end{tabular}

Table 2: Building Parameters

\begin{tabular}{|l|l|}
\hline Total Single Floor Area & $834 \mathrm{~m}^{2}$ \\
\hline No. of Floors & $4 \& 20$ stories \\
\hline No. of Apartments / floor & 4 \\
\hline Area of each apartment & $170 \mathrm{~m}^{2}$ \\
\hline No. of Occupants & 6 \\
\hline Wall Construction U-value & $0.64 \mathrm{~W} / \mathrm{m}^{2} . \mathrm{K}$ \\
\hline Roof Construction U-value & $0.52 \mathrm{~W} / \mathrm{m}^{2} . \mathrm{K}$ \\
\hline Lighting intensity & $25 \mathrm{~W} / \mathrm{m}^{2}$ \\
\hline $\begin{array}{l}\text { Indoor design temp. cooling / } \\
\text { heating }\end{array}$ & $24 \mathrm{C} / 21 \mathrm{C}$ \\
\hline Electrical Equipment intensity & $2.7 \mathrm{~W} / \mathrm{m}^{2}$ \\
\hline Fresh Air & $7.1 \mathrm{~L} / \mathrm{s} /$ person \\
\hline Cooling System & $\begin{array}{l}\text { Air Cooled Chillers }+ \\
\text { FCU }\end{array}$ \\
\hline Heating System & $\begin{array}{l}\text { Central Heating Boilers } \\
+ \text { FCU }\end{array}$ \\
\hline
\end{tabular}

Table 3: Glass Combination

\begin{tabular}{|c|c|c|c|}
\hline $\begin{array}{c}\text { Combination } \\
\text { Number } \\
(\mathrm{CN})\end{array}$ & $\begin{array}{c}\mathrm{U} \text {-value } \\
\left(\mathrm{W} / \mathrm{m}^{2} . \mathrm{K}\right)\end{array}$ & S.C. & Comment \\
\hline 1 & 3.4 & 0.25 & $\begin{array}{c}\text { Reference values for } \\
\text { calculating the energy } \\
\text { saving }\end{array}$ \\
\hline 2 & 3.1 & 0.24 & \\
\hline 3 & 2.8 & 0.23 & \\
\hline 4 & 2.5 & 0.22 & \\
\hline 5 & 2.1 & 0.21 & \\
\hline 6 & 1.8 & 0.2 & \\
\hline 7 & 1.5 & 0.19 & \\
\hline 8 & 1.3 & 0.18 & \\
\hline 9 & 1.1 & 0.17 & \\
\hline
\end{tabular}

\section{Results and Discussion}

The total, cooling and heating, loads of the building vs. glass solar properties are plotted for Jordan climate each with five different glass ratios (20, 40, 60, 80, and $100 \%)$. Results for Moderate Climate in Amman Jordan are presented in Figures 2 and 3 .

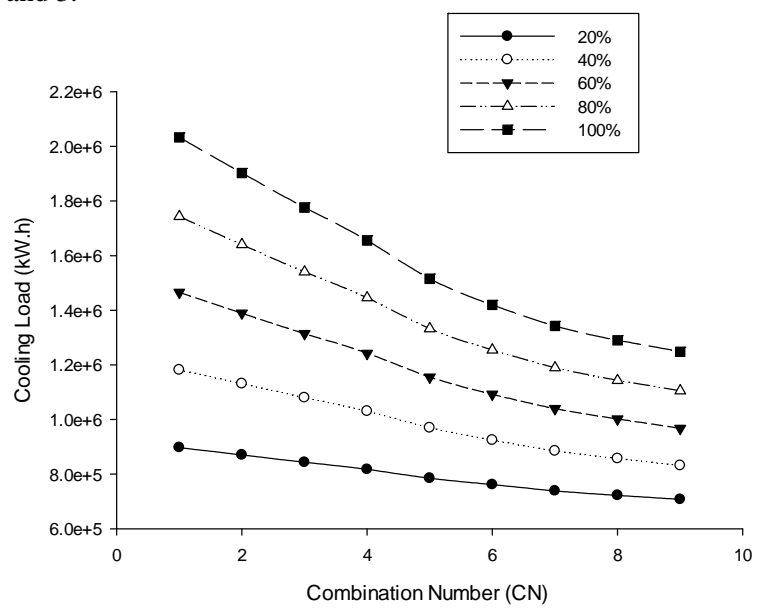

Figure 2: Total, Cooling and Heating, Loads for 4-story building at moderate climate for different glass to wall ratio. 


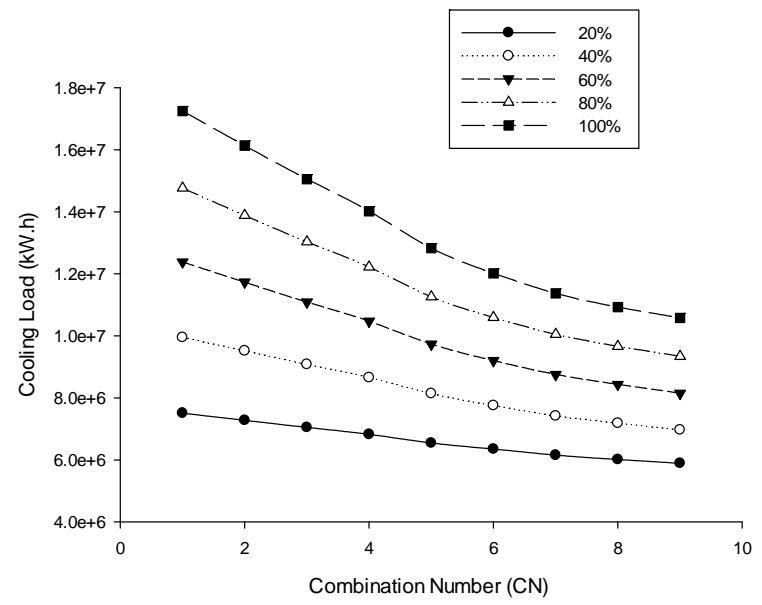

Figure 3: Total, Cooling and Heating, Loads for 20-story building at moderate climate for different glass to wall ratio.

Figure 2 represents the total, heating and cooling, load for 4story building for the all glass to wall ratio versus Combination Number. It can be seen that by increasing glass to wall ration the thermal load increases. Improving glass properties, represented by Combination Number, reduces the total load needed to cool or heat this building, at high glass to wall ration improving glass properties have a significant effect on the building load. The relation between cooling load, $\mathrm{CN}$ and glass to wall ratio are correlated as the following for the case of 4-story building, with $\mathrm{R}^{2}=0.949$.

$$
\begin{aligned}
& 4 \text { Story Total Load }= \\
& \qquad 915514-(63546 * C N)+(9770 * \text { Glass to wall })
\end{aligned}
$$

Energy demand trend shown in fig. 2 can be seen in fig. 3, where it represents the total, heating and cooling, load for 20-story high-rise building for all glass to wall ratio versus Combination Number. It can be seen that by increasing glass to wall ration the thermal load increases. Improving glass properties, represented by Combination Number, reduces the total load needed to cool or heat this building, at high glass to wall ration improving glass properties have a significant effect on the building load. The relation between cooling load, $\mathrm{CN}$ and glass to wall ratio are correlated as the following for the case of 20-story building, with $\mathrm{R}^{2}=0.949$.

\section{Story Total Load $=$

$$
7638346-(540386 * \mathrm{CN})+(84090 * \text { Glass to wall })
$$

These data can be rendered in way that is more useful by finding the energy saving by using each combination number compared to the reference CN. These saving will be reflected in LEED point gained by using each $\mathrm{CN}$.

\section{Case 1}

$20 \%$ glass to wall ratio. Total, heating and cooling, load saving reflected on LEED point achieved by these saving for 4-story and 20 -story building.

Total loads savings, presented in fig. 4, and was calculated by finding the difference between total load for each combination number and the reference $\mathrm{CN}$ load divided by the total load for the reference CN. It was found that, for the case of $20 \%$ glass to wall ration improving glass properties could get up to 10 LEED points.

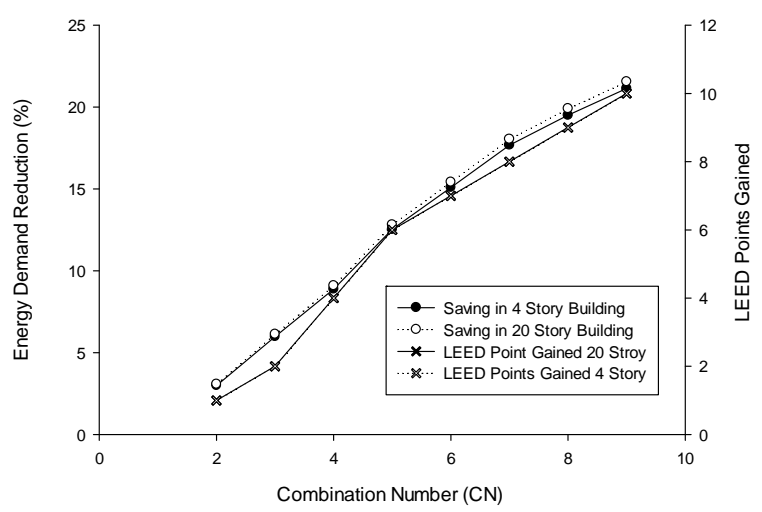

Figure 4: Saving achieved by changing CN compared to reference CN for moderate climate $-20 \%$ Glass in total, cooling and heat, load with LEED point achieved by this saving.

\section{Case 2}

$40 \%$ glass to wall ratio. Total, heating and cooling, load saving reflected on LEED point achieved by these saving, for Moderate Climate in Amman Jordan are presented in Fig. 5.

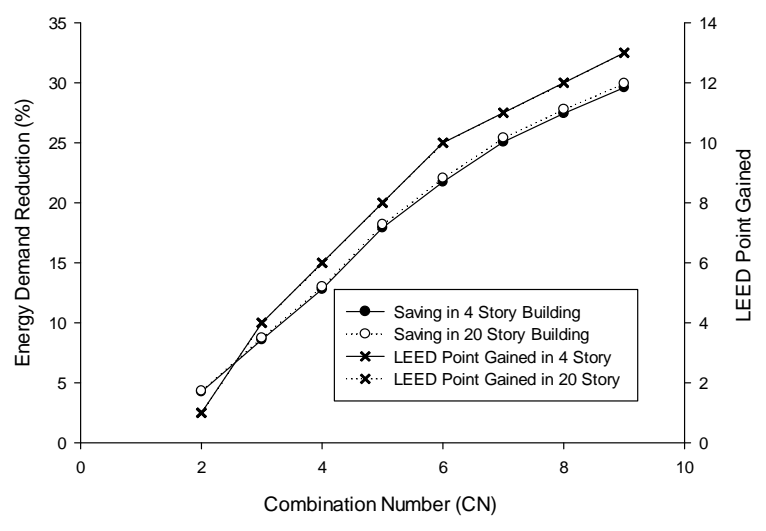

Figure 5: Saving achieved by changing CN compared to reference CN for moderate climate $-\mathbf{4 0} \%$ Glass in total, cooling and heat, load with LEED point achieved by this saving.

Figure 5 depict the energy saving and LEED point achieved by these savings for the case of $40 \%$ glass to wall ratio. The maximum LEED point that could be achieved for both 4-story and 20-story building was 13 point.

Case 3

$60 \%$ glass to wall ratio. Total, heating and cooling, load saving reflected on LEED point achieved by these saving, for Moderate Climate in Amman Jordan are presented in Fig. 6. 


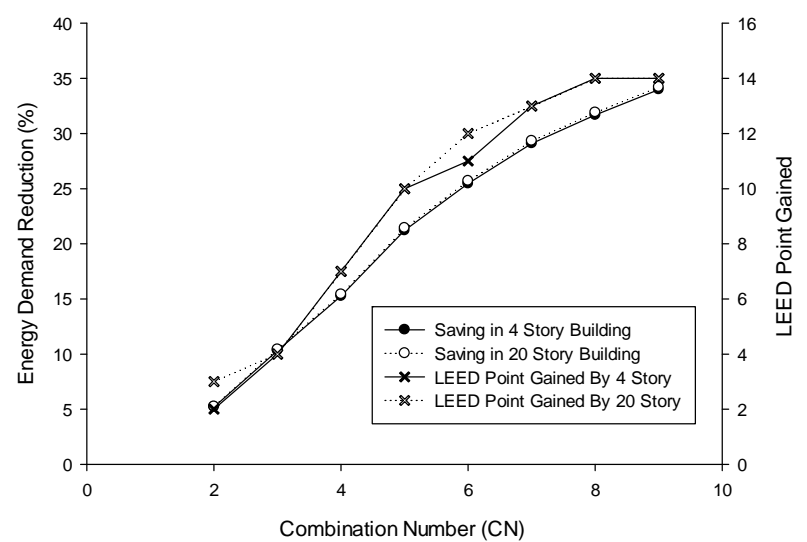

Figure 6: Saving achieved by changing $\mathrm{CN}$ compared to reference CN for moderate climate - $60 \%$ Glass in total, cooling and heat, load with LEED point achieved by this saving.

Energy saving and LEED point achieved by changing $\mathrm{CN}$, for the case of $60 \%$ glass to wall ratio, are presented in Figure 6. Saving increased by increasing the $\mathrm{CN}$ until reaching $\mathrm{CN} 8$, where saving levels off. Based on that it is not recommended to improve glass properties beyond CN 8. The maximum LEED point achieved was 14 for both 4 and 20 Story building.

\section{Case 4}

$80 \%$ glass to wall ratio. Total, heating and cooling load saving reflected on LEED point achieved by these saving, for Moderate Climate in Amman Jordan are presented in Fig. 7.

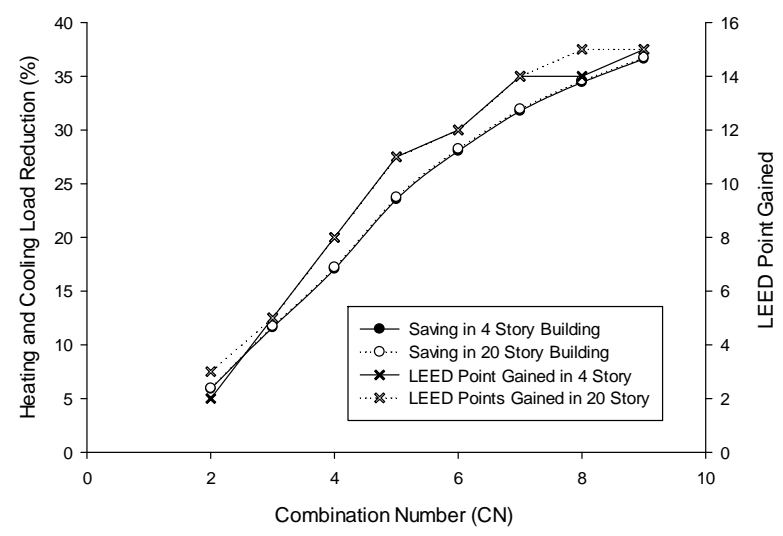

Figure 7: Saving achieved by changing $\mathrm{CN}$ compared to reference CN for moderate climate - 80 \% Glass in total, cooling and heat, load with LEED point achieved by this saving.

Saving in total load curve for the case of $80 \%$ glass to wall ratio is presented in Figure 6. The maximum LEED point achieved was 15.

\section{Case 5}

$100 \%$ glass to wall ratio. Total, heating and cooling load saving reflected on LEED point achieved by these saving, for Moderate Climate in Amman Jordan are presented in Fig. 8.

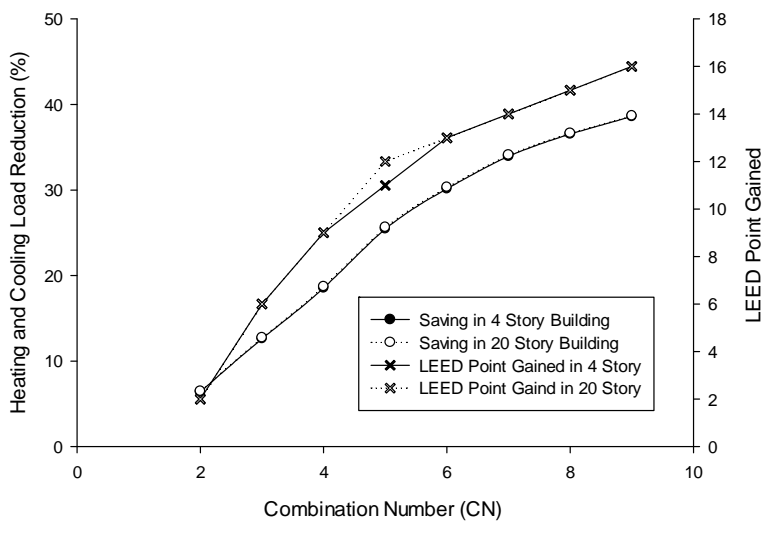

Figure 7: Saving achieved by changing CN compared to reference CN for moderate climate - $100 \%$ Glass in total, cooling and heat load with LEED point achieved by this saving.

Almost the same behavior of $80 \%$ glass to wall ratio can be seen here. The maximum LEED point achieved was 16.

\section{Conclusion}

The effect of glass solar properties on the total, cooling and heating, load on different glass-wall ratios was investigated for 4 and 20-storey residential building in moderate (Amman, Jordan) climate. The relation between cooling and heating load versus glass to wall ratio and glass thermal properties correlated.

The results have shown that enhancing the glass solar properties will substantially effect on the LEED point achieved. Number of the building story did not have a significant effect on LEED points gained and therefore, it can be assumed a maximum of 10 point can be achieved for $20 \%$ glass to wall ratio, a maximum of 13 point for $40 \%$ glass to wall ratio, a maximum of 14 point for $60 \%$ glass to wall ratio. A maximum of 15 point for $80 \%$ glass to wall ratio and a maximum of 16 point for $100 \%$ glass to wall ratio.

Energy saving for case of $20 \%$ wall to glass ratio the effect of glass properties was found to be marginal, on the other hand the case of $100 \%$ glass improving glass properties have significant effect on heating and cooling loads.

\section{Nomenclature}

HAP 4.5

Carrier's Hourly Analysis Program version 4.5 is two powerful tools in one package. HAP provides versatile features for designing HVAC systems for commercial buildings. It also offers powerful energy analysis capabilities for comparing energy consumption and operating costs of design alternatives

U-Value

overall heat transfer coefficient

\section{S.C. Shading coefficient}

SUNCODE-PC ${ }^{\circledR}$ is an hourly building energy simulation program that aids in the design of small energy-efficient buildings where the loads 
are dominated by the dynamic interactions between the building's envelope, its environment, and its occupants

D65

CIE

ASHREA

LEED

FCU refers to an average of eight color samples at $6500 \mathrm{~K}$ color temperature

international commission on illumination standard for color spacing

Energy Standard for Buildings except LowRise Residential Buildings

Leadership in Energy \& Environmental Design

A fan coil unit (FCU) is a simple device consisting of a heating or cooling coil and fan. It is part of an HVAC system found in residential, commercial, and industrial buildings

\section{References}

[1] Ministry of Energy and Mineral Resources of Jordan, Energy Balance, Retrieved March 10, 2013 from http://www.memr.gov.jo.

[2] ASHRAE, ASHRAE Standard 62.1, Minimum Ventilation Requirement and Indoor Air Quality, 2007.

[3] ASHRAE, ASHRAE Handbook- Fundamentals, CH.17-Cooling heating load estimation, 2009.

[4] Jordanian National Building Codes, Thermal Insulation Code, $2^{\text {nd }}$ edition, 2009.

[5] C.K. Cheung, R.J. Fuller, M.B. LutherEnergyefficient envelope design for high-rise apartments, 2005.

[6] Mohammad S. Al-Homoud, Optimum thermal design of air-conditioned residential buildings, 1997.
[7] Mehlika N. Inanici, F. Nur Demirbilek, Thermal performance optimization of building aspect ratio and south window size in five cities having different climatic characteristics of Turkey, 1998.

[8] Hong, T., Chou, S. and Bong, T., (1999), A design day for building load and energy estimation, Building and Environment, Vol. 23 PP. 358_366.

[9] Flodberg, K., Blomsterberg, A. and Dubois, M., Low-energy office buildings using existing technology: simulations with low internal heat gains. International Journal of Energy and Environmental Engineering, 2012 3:19, doi:10.1186/2251-6832-319.

[10] Magli, S., Lodi, C., Lombroso, L., Muscio, A., Teggi, S., Analysis of the urban heat island effects on building energy consumption, International Journal of Energy and Environmental Engineering (2015) 6:9199 DOI 10.1007/s40095-014-0154-9.

[11] Valdiserri, P., Biserni, C. and Garai, M., Energy performance of a ventilation system for an apartment according to the Italian regulation, Int J Energy Environ Eng, DOI 10.1007/s40095-014-0159-4.

[12] E20-II HAP (Hourly Analysis Program) - 8760 Hour Load \& Energy Analysis. Published 2003. Carrier. Visited May 7, 2003

[13] E20-II HAP (Hourly Analysis Program) - 8760 Hour Load \& Energy Analysis. Updated Dec. 9, 2002. Carrier. Visited May 7, 2003 $<$ http://www.carrier.be/dealerbe/e20view.htm>.

[14] Rey, F., Velasco, E. and Varela, F. (2007) Building Energy Analysis (BEA): A methodology to assess building energy labelling, Energy and Buildings, Volume 39, Issue 6, June 2007, Pages 709-716.

[15] Sait, H. (2013), Estimated Thermal Load and Selecting of Suitable Air-conditioning Systems for a Three Story Educational Building, Procedia Computer Science, Volume 19, 2013, Pages 636-645. 